\title{
The Little Word "as." On Making Contexts and Aspects Explicit
}

\section{Konrad Werner ${ }^{1}$}

Received: 16 November 2018 / Accepted: 19 April 2019 / Published online: 29 April 2019

(c) The Author(s) 2019

\begin{abstract}
The word "as" enables one to make contexts and aspects of things explicit while attributing properties or descriptions to them. For example "John is rational as a mathematician"; "John is irrational as a driver." This paper examines the idea according to which all propositions containing "as" should be targeted as potential inferences about the subject; as for the examples given-about John. If the inference is valid - the conception in question holds-one can get rid of "as." I argue against that view by bringing up several contexts in which "as" is not supposed to express an inference. On this basis I come up with a different (non-inferential) typology which does justice, I believe, to ordinary as well as philosophical uses of the little word at stake.
\end{abstract}

Keywords As · Qua · Qua-object · Qua-theory · Aspect · Aspectual shape · Seeing-as

\section{The Question of "as." Some Introductory Remarks}

My friend John is a rational person. I am poised to defend this claim if needed. However, there might be situations in which I would have to say something more specific, for example that John is rational as a mathematician, but at the same time, I would have to admit that he is not rational as an investor or as a driver. To begin with, such propositions manifest a certain manner of looking at the object, thereby serving as indicators of aspects of things, i.e. their modes of presentation, or roles played by things, finally as indicators of contexts. Hence, "as" enables one to make contexts, roles and aspects explicit while attributing properties or descriptions to things. From a different angle, an "as-phrase," e.g. "as a mathematician," or "as a driver," additionally qualifies the attribution of properties.

Konrad Werner

konrad.t.werner@gmail.com

1 University of Warsaw, Krakowskie Przedmieście 3, 00-927 Warsaw, Poland 
There are frequent uses of "as" in the philosophy of perception, inspired by Ludwig Wittgenstein's elaboration of so-called aspectual seeing (Wittgenstein 1958; see also Budd 1987; Day and Krebs 2010), i.e. cases in which one and the same figure can be perceived in at least two ways. The most famous example coming from Joseph Jastrow is a drawing that can be recognized once as a duck, and another time as a rabbit. John Searle (1992) and Tim Crane (2001) both use "as" in their conceptions of mind and intentionality. According to Searle intentional content is genuinely, as he says, aspectual which means that seeing is always "seeing as"; thinking is always "thinking as", etc. Hence, every intentional state has an aspectual shape (Searle 1992: 131). Fred Dretske (1995) follows Searle and makes use of "as" in his theory of representations. Generally, "as" is widely conjoined with the problem of categorization: it is claimed that when I see something e.g. as a rabbit, I spontaneously conceptualize the perceived fragment of reality (for a non-representational, enactive account of "seeing as" see Shani 2010; Werner 2014). For Wittgenstein, however, seeing-as is more like an "amalgam" of seeing and thinking (Wittgenstein 1958, p. 197). ${ }^{1}$

More generally, "as" is one of key words in philosophy when we are determined to articulate possible differences between a thing as it is in itself and the thing as it is for us. For example, we read:

(...) our cognition is directed toward the world in a certain way: it is directed toward the world as we experience it. For example, we perceive the world to be three-dimensional, macroscopic, colored, etc.; we do not perceive it as composed of subatomic particles" (Varela et al. 1991, p. 52; my highlights)

In transcendental reflection we consider the perceived as perceived, the predicated as predicated, the articulated $a$ s articulated, the pictured as pictured (...) (Sokolowski 1984, p. 128; my highlights).

As a contribution to the metaphysical vocabulary, additional qualification was extensively used already by Aristotle. In this field, however, people are more familiar with Latin "qua," beginning with the Aristotelian phrase "being qua being" (see Benardete 1989; Poli 1999; Bäck 1991, 2004). According to the dictionaries "qua" means "in the capacity of", "as being" (Oxford Dictionaries) or "in the character or role of" (Merriam-Webster). In practice, "qua" and "as" are frequently used interchangeably.

Though quite often used, "the little word 'qua", as Barnes (2000, p. 42) nicely refers to it, is quite rarely addressed by philosophers and logicians in their own rights. However, they cannot be regarded as completely neglected either. It is

\footnotetext{
1 Noteworthy, there is a movement, especially in the philosophy of perception, seeking to reconcile the intuition that we are directly acquainted with the world surrounding us, with the apparent aspectual or perspective-dependent character of this acquaintance; to acknowledge aspectual shape of perception while, as Schellenberg (2008) puts it, holding on to the view that subjects directly perceive physical objects (see Crane 2006; Brewer 2007; Cohen 2010; McDowell 2013; Genone 2014).
} 
interesting to note that the reflection on "qua", although it has never become a leitmotif of philosophy and logic, nonetheless has a very long history-the first thinker to investigate "qua" and related connectives was Aristotle ${ }^{2}$ (first of all in Prior Analytics I 38; modern analyses in Annas 1976; Angelelli 1978; Benardete 1989; Poli 1994, 1999; Duarte 2007; Bäck 1991, 1996, 2004, 2014) and his contribution in this field still is the central point of reference.

More recently, "qua" has been brought up by Kit Fine (1982), ${ }^{3}$ and David Wiggins (1980). Colin Marshall (2013) has taken Fine's route in reading Kant, and Simon Evnine (2009) has done likewise in esthetics. Moreover, Ignacio Angelelli (1967a, b), and Philipp Blum (unpublished) too, point to "qua" in the analysis of Frege's notion of sense. Some of these diverse perspectives have been rounded up by Roberto Poli $(1994,1999)$ coming up with the idea of a logico-philosophical qua-theory.

Here, I am not due to provide a historical study. And for my purposes I find the word "as," instead of "qua," more convenient. The variety of applications of "as" brought up above sufficiently justifies, in my opinion, the need of a more elaborate philosophical analysis of this connective (for more, see e.g. Poli 1999).

Traditionally the crucial thing, i.e. the first thing that has to be addressed, is whether an inference from the additionally qualified proposition to the standard proposition is valid (see Maritain 1937; Barth 1974; Tapscott 1976; Angelelli 1967a, b, 1978; Poli 1994, 1999; Bäck 1996). ${ }^{4}$ In other words, whether we can get rid of the additional qualification. For example, one might argue that if John is rational as a mathematician, then John is rational. And if Socrates as a rational being is risible, then Socrates is risible. These propositions single out properties of things that are exposed in but not dependent on contexts. Therefore, the as-phrase "simply comments on the relation of subject and predicate, and does not change their reference" (Bäck 1996, p. 515). ${ }^{5}$ Hence, in this approach, when I speak of John as a mathematician I mean something like "provided that John is a mathematician...." (see Poli 1999 , p. 249), and the additionally qualified proposition is expected to work as a fast and frugal way of expressing short inferences; a kind of implicit reasoning, or,

\footnotetext{
2 Aristotle was also, most likely, the first to make a systematic use of "qua" (however, according to Mates 1986 we can find it in Plato), not only in his characterization of metaphysics (Metaphysics IV), but also in his philosophy of mathematics (Metaphysics XIII and XIV), and physics (Physics 201a 28-35).

As indicated by Bäck (1996), the list of medieval thinkers addressing "qua" includes all the major figures of that period. In Renaissance, in step with a more general criticism of the Aristotelian tradition and scholastic intricacies, formal analyses of reduplication were often dismissed (Bäck 1996: 505). This tendency would later take the shape of a certain reluctance in outlining qua-related and eventually incur an outright rebuke from Frege (1893: xxiii-xxiv).

3 Recently Fine has returned to the issue of qua-objects in his ontology of actions, presented at the Social Ontology Conference in Boston, 2018. The unpublished paper "Acts and Embodiment" is available here: https://www.academia.edu/35032853/acts_and_embodiment.pdf.

${ }^{4}$ Historically, much attention was given to cases where such an inference is a fallacy, known as the fallacy of secundum quid ad simpliciter (i.e. from the qualified statement to the unqualified).

5 For the record: Bäck's original target was "qua," not "as.".
} 
as Bäck puts it, a "condensed syllogism” (Bäck 1996, p. 28). If it fails to function in this way, i.e. when its conclusion is false, we learn that the ascribed property is context-dependent. For example, when I say that taking drugs is good as part of a prescribed treatment, it does not imply that taking drugs is good simpliciter. ${ }^{6}$

Meanwhile, I shall argue that the additional qualification provided by "as" is of three kinds (see also Werner 2014), and only one of them can be unpacked inferentially. They differ when it comes to that which gets changed due to the introduction of "as"; that which, as a matter of fact, is additionally qualified. As for the example given, ( $i$ ) it may not be enough to say that John is rational if what I mean is John playing a certain role or John under a certain aspect, e.g. John as a mathematician; hence, in this case "as" additionally qualifies the grammatical subject. (ii) It may not be enough to say that John is rational if I also want to provide a reason for such a property ascription or if the latter requires an outline of contexts or circumstances to the effect that, e.g. John is deemed rational because he is so successful in tackling problems in universal algebra, but it might no longer be adequate to say that he is rational when it comes to driving; here "as" additionally qualifies predication itself, i.e. the ascription of properties or descriptions. Finally (iii), it may not be enough to say that John is rational if I want to stress the fact that the rationality characterizing John is of some specific sort, e.g. a rationality specific to mathematicians, different from the one specific to investors or drivers; here "as" additionally qualifies the predicate that is actually ascribed.

\section{What Can We Expect from Additionally Qualified Propositions?}

To begin with, I will show that one and the same additionally qualified proposition can be understood as a "condensed" inference at one occasion, and in a noninferential way at some other point. In order to give the reader a sense of how this is possible, I will bring up three scenarios of thinkable real-life conversations. These scenarios are supposed to examine our intuitions, thus, deliberatively, I undertake here a quite old-fashion philosophical analysis.

\section{Conversation 1}

Person 1: We need someone really rational for this job, after all, we're responsible for people's money.

\footnotetext{
${ }^{6}$ Traditionally, the first line is drawn between reduplicative additional qualification, for example when someone declares "All men are equal as men" and non-reduplicative ones. Reduplicative propositions can serve to draw the line between context-independent and context-dependent property ascription: when one says that all men are equal as men, one likely wants to make clear that in his/her view each human being has certain fundamental rights precisely by virtue of being a human being; one wants to stress the fact that people do not merely manifest their moral status in this or that context but that they genuinely possesses this status (see e.g. Poli 1999). In this article, however, I shall address only the non-reduplicative propositions.
} 
Person 2: What do you think about John? He is rational as a mathematician.

Person 1: Yes, true, he is rational as a mathematician. I'm going to make him an offer and we will see.

\section{Discussion}

In this conversation John's being a mathematician serves as a premise, or as a justification for attributing rationality to him. This is because all mathematicians are supposed to be rational. The two speaking persons make a quick inference as a result of which they conclude that John is rational: all mathematicians are rational, therefore if John is a mathematician, then he is rational. The additionally qualified proposition is useful as long as it allows us to express such a quick inference in a single sentence instead of three. Nonetheless, since the additional qualification here serves as a middle term in a syllogism, traditionally speaking, it is no longer important for the conclusion. The speakers are interested in John's property, thus, their conclusion refers to John, and once the conclusion is reached, "as" is of no relevance anymore and can be dropped off.

\section{Conversation 2}

Person 1: We need someone really rational for this job, after all, we're responsible for people's money.

Person 2: What do you think about John? He is rational as a mathematician.

Person 1: Yes, true, he is rational as a mathematician. But he might not be so rational in doing this particular job.

\section{Discussion}

Note that in this conversation Person 1 takes the additional qualification pertaining to John's rationality not as a justification for attributing rationality to John himself, but rather as a way of stressing the fact that John is rational as long as he plays the particular role or as long as we focus on the mathematics-related aspect of John, as it were, but he may not be rational when playing a different role or under a different aspect. Person 1 is apparently not interested in inferring anything about John himself; nothing is stated about John himself but only about John as playing certain roles or John as exhibiting a certain aspect. Therefore the additional qualification is not eliminated-it is an irreducible component of this conversation's conclusion. 


\section{Conversation 3}

Person 1: We need someone really rational for this job, after all, we're responsible for people's money.

Person 2: What do you think about John? He is rational as a mathematician.

Person 1: Yes, true, he is rational as a mathematician. But I'm not sure if a man who is used to manipulating theoretical fictions and abstract ideas should be responsible for real people's real money.

\section{Discussion}

In this conversation Person 1 is interested neither in proving John's rationality nor in limiting his rationality to certain roles; the conclusion rather pertains to the fact that there is a special kind of rationality that is characteristic of mathematicians and that some other kind of rationality is needed for this particular job. Hence, "as" is still an irreducible component of the conclusion, however, here it does not add anything, as it were, to John; instead, "as" adds something to the property ascribed.

Generally, as we have just seen, one and the same additional qualification can be understood in three different ways, giving rise to three different responses, depending on context. Imagine that an engineer is supposed to come up with an algorithm that could decide whether or not someone should be hired, thereby making human recruiters dispensable. The algorithm would have to be able to distinguish the mentioned three senses of additionally qualified propositions.

Hence, in my understanding, the first thing that any theory of additional qualification should do is to account for the elicited diversity.

\section{Three Kinds of Additional Qualification}

One can seek to formalize the use of additional qualification by using the formal tools of predicate logic, as Angelelli (1978) and Bäck (1996) do, but this is not my purpose here. I conduct my analysis in natural language, particularly due to the fact that choosing a specific formal apparatus may not be philosophically innocent, so to speak. Here is a good example. When we take the expression "John is rational as a mathematician" at face value, i.e. without any ready-made template provided by a specific formalization, it is not exactly clear to which part of the sentence the as-phrase is attached: it can be considered as attached to the proposition "John is rational" as a whole or to the predicate "rational" alone. If truth be told, this issue is not exactly clear in the traditional approach, too. On the one hand, for Bäck it is clear that, according to Prior Analytics I. 38, the as-phrase is to be attached to the predicate (Bäck 1996, p. 31), on the other hand, however, Bäck characterizes the additionally qualified proposition as a proposition that "qualifies the relation of the predicate to the subject" (Ibid., p. 1; my highlighting). Apparently he deems these 
two scenarios equivalent if approached from the standpoint of modern logic. The latter differs, however, from the traditional logic where the $a s$-phrase forms a syntactic unit with the predicate. Yet, the problem is that the complex predicate "rational as a mathematician" has "logical drawbacks," as Bäck (Ibid., p. 517) puts it, from the standpoint of modern logic, firstly because it must be introduced not as a derived sign, but as a basic, non-standard sign; and secondly, the relation between the components of this non-standard complex predicate can hardly be made clear in the analysis provided by predicate logic.

The issue becomes even more complex once we realize that while "John is rational as a mathematician" seems to be equivalent to "John as a mathematician is rational," the latter brings one more option as to what is the as-phrase attached to, namely it can be attached to the grammatical subject, e.g. to "John."

Therefore, I shall stay at the level of natural language not because I find formalization undoable, but because it should not be too hasty, so to speak. My initial belief is that instead of trying to reduce the diversity of places in which the as-phrase can be located, we should explore it first.

\subsection{Ascribing Properties to Qua-Objects}

I add parentheses (,) to make an order within the proposition more visible. So, going back to our example, think first of the proposition "(John as a mathematician) is rational." Note that the expression "John as a mathematician" is a well-formed formula in English on its own right, yet, apparently "as" is not a sentential connective here-_John as a mathematician" is not a sentence; instead, it works as a complex name, and therefore it refers to an object of some sort.

Kit Fine (1982) calls this special kind of referents qua-objects. According to Fine, for any standard object, like a man or a table, and its property or description, we can construe a qua-object-for example, John qua mathematician, John qua prime minister, but also — which admittedly may look unnatural in English — the apple qua red, the ball qua round, etc. In accordance with the convention I employ here, I shall replace "qua" with "as." Inside the qua-object Fine calls the left side a base and the right side a gloss. Hence, John is the base of the qua-object "John as a mathematician" while "mathematician" is the gloss which, in my understanding, manifests a particular aspect of John. A qua-object is not numerically differentiated from its base: it is numerically the same thing, albeit with one of its properties, aspects or descriptions exposed. As Fine proposes, the qua-object can be described as an amalgam of the given object and the property, as the given object but "wearing the property on its face" (Fine 1982, p. 100).

Although the category of qua-object may seem a philosophical extravagancy, Fine introduces it in order to account for the metaphysical construction of ordinary things that "cluster up our daily life" (Ibid., p. 97). Namely, qua-objects are supposed to reveal the formal-material structure of ordinary things (see Fine 1994); that is to say, as Aristotle stated, the fact that things are always composed of some matter or substrate and of a form or shape. Think of Michelangelo's David. What we call David can be re-recognized as the qua-object composed of the given portion 
of marble (serving as the base) equipped with the appropriate properties of shape (serving as the gloss). David is an amalgam of the base and the gloss, Fine would say. Therefore, a qua-object cannot be identified with or reduced to its base (the statue is not merely the given portion of marble), nor to its form (a perfect copy of the statue is not the statue). Moreover, according to the inheritance principle outlined by Fine, qua-objects possess all the properties possessed by their bases, but not vice versa: a piece of marble as shaped thus and so may be a groundbreaking piece of art, but the marble is not a groundbreaking piece of art.

However, the categories of matter/base and form/gloss do not refer only to such things as monuments, sculptures or paintings. John as a mathematician cannot be reduced to John since John could lose, e.g. due to some brain damage, all of his professional knowledge and skills (thus John as a mathematician would cease to exist), yet supposedly (let's put aside the problem of personal identity for a moment) John would still remain.

Fine's context is different than mine. I do not intend to dig into the metaphysical details of his idea and discuss its plausibility. Blum (unpublished) pays much attention to this issue. I just hold that the qua-object is a thinkable structure which might be brought to light in additionally qualified propositions. So, the first template for a proposition of this kind may be regarded as the ascription of a property to the quaobject (hereafter PQ). By using this template, for example in "(John as a mathematician) is rational" we can stress the fact that the ascribed property, e.g. rationality, does not characterize the object per se, thus the base, but only the object exhibiting a certain property or aspect "on its face". 7 So, when I say "(John as a mathematician) is rational" I do not attribute rationality to John, maybe because I am also aware of some of his irrational aspects. I attribute rationality exclusively to the amalgam of John and one of his aspects or only to John playing this particular role.

Note that when it comes to PQ, the inference from the additionally qualified proposition to the standard proposition is not merely false-it is out of the question due to the very nature of qua-objects. If we unpack Michelangelo's David as the quaobject "this piece of marble as shaped David-wise (by Michelangelo)," we can say, for example, that this piece of marble as shaped David-wise is a priceless work of art. From the latter, as already mentioned, we can hardly drive the conclusion that the piece of marble is a priceless work of art. The conclusion is false, of course, but the triviality of its falseness teaches us, in my understanding, that additionally qualified propositions such as the one referring to David are not-in principle-candidates for inferences. They constitute a different kind of additionally qualified propositions.

\subsection{Two More Options: Additionally Qualified Properties and Ascriptions Thereof}

Let us now consider the proposition of the form "(John is rational) as a mathematician." Note the difference: here the additional qualification does not pertain to the object itself, but to the attribution of the property or description. This is the best

\footnotetext{
7 The metaphorical idea of objects wearing some of their properties on their faces could likely be thought of as the objects' affordances_-in the spirit of Gibson's (1979) famous proposal.
} 
template if one wants to outline the context or circumstances of the property ascription or if one wants to pinpoint the reason why the ascription is the case. We can read it as "the object is such and such in the context/circumstance thus and so," or as "taking such and such circumstances into account, the object is such and such", e.g. "taking into account that John is a mathematician, he is (can be regarded as) rational." Finally, a stronger connection would be something like "the object is such and such in virtue of this or that," e.g. "John is (or can be regarded as) rational in virtue of his being a mathematician." I provisionally call this kind of additionally qualified proposition "aspredication" (hereafter AP).

To see the difference between AP and PQ, let me refer once again to the conversations that I brought up above. In Conversation 1 the two speakers are inclined to ascribe rationality to John under certain conditions. In accordance with AP, the additional qualification "as a mathematician" indicates these very conditions (or just one condition that the speakers find sufficient). Hence, they say "(John is rational) as a mathematician," thereby articulating a short reasoning about John. As result, John is deemed rational and gets the job. In Conversation 2, on the other hand, the two speakers are still interested in attributing rationality, however, in accordance with PQ, they restrict it only to John playing a certain role or to John exhibiting a certain aspect. They say "(John as a mathematician) is rational." And since the job requires John to play a different role or to "wear" a different aspect, as Fine (1982) could say, he won't get the job.

Finally, as already announced, the $a s$-phrase may be seen as attached to the predicate thereby providing an additional qualification to the property ascribed, e.g. "John is (rational as a mathematician)". Hence, in PQ we get an additionally qualified object (a qua-object) to which some property is ascribed; in AP we get an additionally qualified ascription of a property or description; finally, here we have an additionally qualified property; to fall in line with Fine's convention, we could dub it "qua-property." I provisionally call the template at stake "attribution of the quaproperty" (hereafter AQ). Hence, "John is (rational as a mathematician)" could be understood as "John is rational but this rationality is specific for mathematicians" (while the rationalities of, say, investors or politicians are of a different sort). Possibly in "(rational as a mathematician)," "rational" might likely be thought of as determinable, while "mathematician" might be thought of as determinate in accordance with the classic distinction made by Johnson (1921).

To see how AQ works, see Conversation 3: the two speakers are again interested in John himself (unlike in Conversation 2), nonetheless, they point not to the universal property that could be instantiated in a large group of cases (determinable), but, in accordance with AQ, to a special subtype of this property (determinate): to the rationality characterizing mathematicians. In effect, John won't get the job insofar as some other subtype of rationality is expected from the candidates. Someone might argue that there is no practical difference between AQ and PQ: in both cases John remains jobless. Note, however, that someone might remind Person 1 in Conversation 3 that the rationality specific to mathematicians could be useful anyway, perhaps in a different section of the company. Meanwhile, such a remark would be pointless in Conversation 2. 


\section{More on How "as" Works: Some More Examples and Discussion}

Having all that in mind, let me elaborate more on a few examples in order to outline a significant philosophical potential of "as" as unpacked above.

\subsection{Playing Roles}

Consider the following sentence:

(1) John is traveling to Brussels as a prime minister.

To begin with, the phrase "as a prime minister" may be very informative, e.g. for someone who knew John first of all as, for example, an admirer of René Magritte, whose works are presented in large numbers at the Royal Museums of Fine Arts of Belgium in Brussels. Admittedly, a person who intends to meet with John and who is well informed about the nature of his trip will be able to make more accurate predictions regarding John's plans than a person lacking this knowledge. The knowledge in question can likely be expressed in many different ways, hence "as" can by no means be cited as a necessary condition for successful communication. Nonetheless, it yields gains to speakers, as it enables two messages that are not incidentally related to each other - the description of the object and an overview of the circumstances in which the description is given - to be conjoined in one relatively simple sentence.

Compare it with three other propositions pertaining to roles, including the one already elaborated on:

(2) John is the head of government as a prime minister

(3) John as a mathematician is rational

(4) Titus as a judge should not accept gifts (an example discussed by Bernard Bolzano 1837/2014)

Someone might claim that (2) is trivial. However, the fact that we would likely recognize the sentence "John is the head of government as a homo sapiens" as false or nonsensical, or at least bizarre, shows that we spontaneously do qualify such predication as "John is the head of government" in such a way as to ascribe it to appropriate contexts, although usually there is no need to make this qualification explicit. Moreover, it is quite easy to think of contexts in which at least some of such seemingly obvious ascriptions are purposely singled out: (2) includes part of the definition of a prime minister (at least in parliamentary systems) and as such is likely to be found in dictionaries, course books, tests, etc.

Now, although all the propositions (1)-(4) refer to roles, they differ in several interesting ways. Firstly, it seems that the additional qualification in (1) can be dropped due to the fact that it depends on a particular moment in time and merely "comments" on the fact that John is on his way to Brussels. So, if John is traveling to Brussels at a given moment $t$ as a prime minister, then John is traveling to Brussels 
at $t$. Even if the conclusion lacks the information pertaining to the role played by John during the trip, the trip itself takes place in the physical reality, thus an implication does occur. Compare it to (2). In (2), we can also drop the as-phrase and conclude that John is the head of government, simpliciter, however in this particular case we lose not only a useful, but a fundamental thing: in (1), whether in this role or another, the man is traveling to Brussels, yet, going back to (2), we cannot say that whether in this role or another he is the head of government. He has this capacity only insofar as he is a prime minister. So, it seems that the implication does occur in (2), nonetheless it clearly differs from the implication in (1).

On the other hand, (2) can be unpacked as a "condensed" reasoning and (1) cannot, which elicits another interesting difference. As for (2) we obtain: if it belongs to the definition of prime minister that he or she is the head of government, and if John is the current prime minister, then John is the head of his government. As for (1), it can hardly be unpacked as a reasoning due to the fact that the premise "All prime ministers are traveling to Brussels" which would be necessarily to run the reasoning strikes us as awkward. If not awkward, it is certainly false since there is no definitional link between being a prime minister and traveling to Brussels. Let me stress this subtle issue: admittedly, there is a strong link between these two things, especially if (1) refers to a prime minister of one of the EU member states, and if, for example, taking part in a meeting of the European Council is the proper purpose of the trip. The link is established by practice and low, yet, still, there is no a priori necessary connection between being a prime minister a taking part in meetings of the European Council, established by the definition of a prime minister, unlike in the case of a prime minister's being the head of a government.

Now let us pay attention to (3) again. As already noted it is possible to read it as a reasoning: John is a mathematician; all mathematicians are rational; therefore John is rational. Hence, it seems that (3) functions in exactly the same way as (2), and perhaps only the conceptual link between being a mathematician and being rational is a bit weaker; i.e. the link is intuitive but, unlike in (2), it is not definitional. However, a more careful scrutiny shows a crucial difference making (3) more in line with (1). Namely, if we target (3) as a reasoning (which is not the only option on the table, as I showed above), and conclude that John is rational, we can really forget about his profession. In other words, rationality is here ascribed to John per se, and the appeal to his profession just "commented" on this fact, as Bäck (1996) might say. (2) differs from (3) in this respect: being the head of government has nothing to do with John per se. Therefore, in spite of the fact that (2) can be sensibly read as a reasoning referring to John who is the head of government, the appeal to his role, i.e. to his serving as a prime minister, is in fact only masked in such a reasoning, but never truly eliminated.

Another interesting example is (4). There seems to be a reasoning: if Titus is a judge; and judges cannot accept gifts, then Titus cannot accept gifts. However, the conclusion strikes us as strange. Bolzano aptly points out that it is not the case that Titus generally should not accept gifts because he is a judge - that would be absurd. On the other hand, Bolzano argues, we can hardly "state of Titus' attribute of being a judge that it (this abstractum) should not accept gifs" (Bolzano 1837/2014, p. 159). What we refer to is not Titus himself, and not his role alone, but Titus playing 
this role. He must not accept gifts insofar as he serves as a judge. Hence, as a matter of fact, there is no reasoning referring to Titus per se in (4).

However, in spite of the crucial difference just mentioned between (4) and all other propositions discussed earlier, there is a certain affinity between (4) and (3). Namely, rationality is likely to be regarded by people as necessary for mathematicians, and, in a similar vein, uncorrupted judgment is likely to be deemed a necessary condition of being a judge. A corrupted judge is not a judge, but only pretends a judge. A mathematician who is incapable of rational thinking cannot be a mathematician. Similarly, a fair-weather friend is not really a friend. Hence, interestingly, there is in (4) an abstract conceptual connection between being a judge and having uncorrupted judgment, grounded in our understanding of these terms, and still there is no implication from the additionally qualified proposition about Titus who, as a judge, should not accept gifts, to the standard proposition about Titus himself.

Bäck addresses Bolzano's (4) in terms of time-relatedness (for Bäck's general account of roles see Bäck 2002). He writes that (4) means in fact that Titus should not accept gifts while he is a judge (see Bäck 1996, pp. 472-3). This view is not satisfactory, though. Note that there is nothing special about any moment in time by itself. Suppose that while Titus was working as a judge some gift was being given to him by his wife who dropped by his office-is there any reason why he should not accept it? If someone wants to protest by saying that such gifts have nothing to do with his being a judge, I am happy to agree, for this is precisely my point-namely, that the acceptance or refusal of gifts, whether or not they are offered during Titus's office hours, must relate to his role. So, the reference to his role is still there; it is indispensable if the phrase "while he is a judge" is to have any meaning-as a matter of fact it does not refer to time.

Now, I shall approach this diversity among the additionally qualified propositions referring to roles from the perspective of my posit, i.e. the distinctions between AP, $\mathrm{PQ}$ and $\mathrm{AQ}$.

Imagine the following two conversations:

\section{Conversation 4}

Person 1: John is the most famous person in Europe right now, I want to see him!

Person 2: John is traveling to Brussels as a prime minister-you know, there is a summit this weekend-so you can see him there.

Here the as-phrase "simply comments" on the relation of John and his traveling. Apparently John is the important thing for Person 1. Hence, AP is at work: (John is traveling to Brussels) as a prime minister.

\section{Conversation 5}

Person 1: Is John about to visit the Royal Museum of Fine Arts this weekend?

Person 2: I don't think so, John is traveling to Brussels as a prime minister.

Here the $a s$-phrase expresses an additional qualification of the travel and Person 2 points out that the character of this particular visit to Brussels rather does not allow John to stop by the Royal Museum and admire Magritte. Hence, AQ seems to be appropriate: John is (traveling to Brussels as a prime minister). 
I have already elaborated on the three readings of (3). When it comes to (2), it seems that there are two options on the table: either we get "(John as a prime minister) is the head of government," and then we are not interested in making any reasoning referring to John per se, but only in him playing his role; or we get "(John is the head of government) as a prime minister," if we want to use his role as a premise in a reasoning referring to John's current capacities, for example when we want to convince someone that John can fire a member of his cabinet. Yes, he can do itsince he is a prime minister, he is the head of the government, and those who head governments can fire other member of these bodies.

Finally, let us look again at Bolzano's (4), i.e. the case of Titus who should accept no gifts as a judge. Revising (4) especially in accordance with the PQ template in my opinion does justice to Bolzano's claim that neither Titus himself nor his attribute or role in abstractum is what we refer to when we state that he should not accept gifts; rather the rule applies to Titus playing the role; to Titus in his judicial aspect. Hence, when I say "(Titus as a judge) should accept no gifts," I mean that Titus presenting himself in his judicial aspect (wearing his judicial aspect on his face, as Fine would likely say) cannot accept gifts, which are supposed to corrupt his judgment. I am not saying anything about Titus himself, and I am not making any inference-I directly recognize Titus exhibiting a certain aspect, thus a qua-object based on Titus, and I attribute a certain obligation to this Titus-based qua-object.

\subsection{Aspects, and "as" Providing Order}

Since the issue of aspects has been already brought up, let us pay attention to it. Consider the two propositions discussed by Poli (1999), based on the example provided by Quine (1960/2013). In Word and Object Quine writes that mathematicians may be said to be necessarily rational and not necessarily two-legged, while cyclists are deemed necessarily two-legged and not necessarily rational. Then he carries on to ask how we should target an individual who counts "among his eccentricities" both mathematics and cycling? (Quine 1960/2013, p. 182)

Poli puts it in the following way:

(5) John is necessarily rational but not necessarily two-legged as as mathematician

(6) John is not necessarily rational but necessarily two-legged as as cyclist

We can see that part of (5) is a modal version of (3). Now, the problem I wish to emphasize is this: while we could, under some conditions, drop the additional qualification in (3), and conclude that John is rational without mentioning his profession (if the AP template applies), apparently we cannot do the same thing in (5): being necessarily rational may be, indeed, attributable to mathematicians, thus also to John as a mathematician, but there is no reason to conclude that John himself is necessarily rational. On the other hand there are reasons to believe that John himself is not necessarily two-legged, yet we don't need the additional qualification "as a mathematician" to know that, for people generally are not necessarily two-legged (those with amputated legs are still human beings, obviously); 
i.e. the $a s$-phrase "as a mathematician" seems rather redundant when we want to speak of John's being two-legged. In sum, if one wishes to read (5) as a "condensed" reasoning, the first conclusion is false (it is false that John per se is necessarily rational even if he $i$ s rational simpliciter) and the other conclusion, i.e. the one saying that John is not necessarily two-legged, does not maintain any significant connection with the premise (i.e. with the fact that he is a mathematician), so, the implication is valid, yet hardly informative.

Someone might disagree and try to make the case that the as-phrase "as a mathematician" in (5) should be interpreted as pertaining to the actual cause of John's necessary rationality. This could mean that, if all mathematicians are necessarily rational, then because John is a mathematician, he is necessarily rational. In other words, his job renders him necessarily rational. Yet, this reading turns out to be problematic once we pay attention to (6). Note that (5) and (6) are structurally identical, and they may be both true, so most likely they should be interpreted in the same way. However, if that is the case, we end up with the conclusion that John is necessary rational derived from (5) and the contradictory conclusion that John is not necessarily rational derived from (6). The same goes for him having two legs.

I believe that the framework proposed by me provides a nice way to unpack Quine-Poli's examples (5) and (6). One option is to concede that there are two different qua-objects: "John as a mathematician" and "John as a cyclist" and that they have different modal properties. Hence we get: "(John as a mathematician) is necessarily rational but not necessarily two-legged" and "(John as a cyclist) is not necessarily rational but necessarily two-legged." Due to the fact that qua-objects, as Fine renders them, may have properties that are not possessed by their bases, there is no contradiction.

Another option, likely more in Quine's original spirit, is AQ. As a fierce opponent of intensional contexts and modal discourse, Quine could be happy to accept that modal predicates are bond to roles and their descriptions, not to individuals. So, in my reading, he could say "John is (necessary rational as a mathematician) but (not necessary two-legged as a mathematician), and "John is (not necessary rational as a cyclist) but (necessary two-legged as a cyclist)." Modal properties are attributed to roles, a Quinean philosopher could say, and due to this bond we evade a puzzling issue of how they could exist in the objects themselves. Whether or not the Quinean thinker is right, there is a template in our toolbox that they can use to make their case.

Bringing up the Quinean cases it is not supposed to make any statement about the nature of modalities or about whether or not Quine was right is his account of modal properties. The latter may be regarded as quite problematic (see e.g. Barcan Marcus 1995). However, I use it here only as an example of how "as" can bring an order to property ascriptions.

Yet, a different question regarding modalities in the context of "as" pertains to such propositions as "It is possible that John is rational as a mathematician" and "It is necessary that John is rational as a mathematician." How do they behave and what is the proper semantics for them? Just note that if we employ the Kripkean possible world semantics, we have two options. If the latter proposition is deemed true, does 
it mean that in all possible worlds John is rational and he is also a mathematician there, or is it sufficient that he is rational in all of them, but he may not be a mathematician in some of the scenarios at stake? Perhaps the weaker condition applies when the as-phrase merely "comments" on the property ascription, yet if the property is attributed to a qua-object, the stronger condition seems to be more appropriate. This is however, just a provisional speculation at this point, which would require more work on its own.

Aside from the issue of modal properties and their status, the crucial thing that becomes apparent once we consider these examples is that "as" provides order and protects our system(s) of beliefs against contradictions. Let us now come back to simpler cases to see this critical function of "as" even better. Compare (3), i.e. "John as a mathematician is rational" with this:

\section{(6) John as an investor is irrational.}

It goes without saying how useful an adequate grasp of the rational and irrational sides or aspects of John can be when it comes to planning actions and making predictions about John's behavior, decisions, etc. Without such knowledge, we might fail at these tasks.

Now, if we pay attention to these cases, it becomes clear that the AP template can only be applied to either (3) or (6) in separation but never in conjunction. As mentioned, one might read (3) as "(John is rational) as a mathematician" and conclude that John is rational. Suppose, however, there is an empirically nailed down connection between being an investor and having a tendency to irrational behavior. Are we equally willing to admit that if (John is irrational) as an investor, then John is irrational? This is an empirical question. But if we are willing to admit John's irrationality, and both (3) and (6) are read in line with AP, then we find ourselves in a pickle because (3) and (6) as they stand - precisely thanks to the as-phrases-can be both true, but their conclusions, if (3) and (6) are taken as "condensed" inferences, cannot both be true. John would be regarded as rational and irrational at the same time.

Targeting additionally qualified propositions in separation does not seem very productive, so to speak, since their ability to provide order to our beliefs becomes explicit when they are rounded up and grouped. The whole advantage of having this little word "as" in our toolbox becomes clear if we consider (3) and (6) together; "as" makes aspect-attribution possible, thereby enabling us to endorse (3) and (6) without the risk of contradiction.

From this angle the two other templates are more promising. In accordance with $\mathrm{PQ}$, when I believe that "(John as a mathematician) is rational and (John as an investor) is irrational, I attribute different properties to different aspectual "manifestations" of John. And in accordance with AQ, when I believe that John is (rational as a mathamatcian) and he is (irrational as an investor) I pertain to two different instantiations of rationality/irrationality. 


\subsection{Matter, Form, and Perception}

Finally, let us go back to the original context that gave rise to Fine's (1982) quaobjects, namely the issues concerning matter and form. Consider the example:

(7) This piece of gold as a mask of Tutankhamen is an ancient work of art

Someone might argue that (7) can hardly be heard in real conversation, and admittedly it is quite unusual from the standpoint of everyday speech, but it is not so difficult to think of a situation in which (7) would not be out of place. Imagine a brash man putting a price tag solely on the piece gold of which the ancient mask is made. Some indignant archeologist might reply: "No, my friend, this piece of gold is priceless but only as a mask of Tutankhamen!"

When the AP template is employed, it seems obvious that the implication from (7) to "This piece of gold is an ancient work of art" does not occur-after all, the piece of gold is not an ancient work of art. But if that is the case, then (7) is lumped with such trivially accidental cases like "John is tall as compared with Marry." Meanwhile, as I already pointed out, the point is not that in (7) the "condensed syllogism" is fallacious; the point is that (7) is not even a candidate for inference about the piece of gold alone. What is special in (7) is that while it cannot disregard the piece of gold and focus solely on the form provided to it by the ancient artist (in Fine's terminology - on the gloss), at the same time it is by no means about the gold: apparently, it is about the mask.

I have already hinted in the paragraph dedicated to Fine that PQ suits such cases as David or Tutankhamen's Mask well. We obtain: "(This piece of gold as a mask of Tutankhamen) is an ancient work of art." Here it is clear that the property of being an ancient work of art is ascribed to the qua-object.

The reason why I come back to this issue, however, departs from Fine's original context and has to do with Wittgenstein's seeing-as. I emphasized above that what was special about attributing a property to the qua-object was that while it could not disregard the base, e.g. the piece of gold, and focus solely on the gloss, e.g. being shaped in the Tutankhamen-wise manner, at the same time it was by no means about the gloss: apparently, it was about the thing, e.g. the mask, considered as a specific amalgam of these two constituents. This issue is somewhat analogous to the problem faced by Wittgenstein when we sought to tackle the question of whether seeing-as was more like seeing itself, or more like thinking or interpreting:

(...) the flashing of an aspect on us seems half visual experience, half thought. (Wittgenstein 1958, p. 197)

But how are these two halves connected?

(...) is this a special sort of seeing? Is it a case of both seeing and thinking?

or an amalgam of the two, as I should almost like to say? (Ibid.) 
The term "amalgam" comes up again. It helps to understand a remark made by Wittgenstein earlier:

It would have made as little sense for me to say "Now I am seeing it as..." as to say at the sight of a knife and fork "Now I am seeing this as a knife and fork". This expression would not be understood.- Any more than: "Now it's a fork" or "It can be a fork too".

One doesn't 'take' what one knows as the cutlery at a meal for cutlery; any more than one ordinarily tries to move one's mouth as one eats, or aims at moving it. (Ibid., p. 195)

It is clear, therefore, that the amalgam at stake cannot be unpacked in terms of me taking something as such and such; interpreting or representing the thing as such and such. The amalgam must be based on the perceived thing itself, while at the same time somehow incorporating what Wittgenstein refers to as "thinking." These two components come as one and manifest themselves when a new aspect shines up. But how are we supposed to make our minds around this peculiar "juncture of the sensory and the intellectual," as M. Budd (1987, p. 2) aptly calls it?

To realize how specific the idea of such a "juncture" or "amalgam" of the sensory and the intellectual is, we must recognize it against some background. Here is how Susana Siegel sees the alternative that any philosophical account of perception faces:

When one speaks of the contents of a bucket, one is talking about what is spatially inside the bucket. An analogous use of "the contents of perception" would pick out what is 'in the mind' when one has a perceptual experience. In contrast, when one speaks of the contents of a newspaper, one is talking about what information the newspaper stories convey. Most contemporary uses of "the contents of perception" take such contents to be analogous to the contents of a newspaper story, rather than the contents of a bucket. This notion of content can straightforwardly accommodate the idea that there is such a thing as the 'testimony of the senses'.

One influential version of the idea that the contents of perception are analogous to the contents of a newspaper story holds that the contents of an experience are given by the conditions under which it is accurate. What an experience conveys to the subject, according to this conception, is that those conditions are satisfied (Siegel 2016).

One who endorses the "bucket theory," to use a phrase once introduced by Karl Popper (1972), neglects the intellectual side of the "juncture." On other side, however, it seems that targeting perception as a "testimony" conveying propositional contents could be approached, from the Wittgnsteinian angle, as taking the opposite route and prioritizing the intellectual over the sensory. The author of "Philosophical Investigations" makes a strong point, however, that one "doesn't 'take' what one knows as the cutlery at a meal for cutlery," meaning that seeing something is not like testing a hypothesis. 
There is no place in this paper to seek a comprehensive account of Wittgenstein's seeing-as, and the literature on this topic is vast (see Day and Krebs 2010 for a collection of new outstanding essays), nonetheless one relatively modest thing I wish to do is to make the case that a closer look at the little word "as" itself could be beneficial to the pursuit in question.

In a nutshell, it seems that the inferential reading of "as" fits well with the idea that perception is a propositional attitude with accuracy conditions. "I perceive this as a fork" could be unpacked as the following inference: I perceive something and I believe that this is a fork (I perceptually "take" the thing for a fork, as Wittgenstein would put it). Now, if the belief is true (its accuracy conditions are satisfied), the conclusion follows that I perceive a fork. Since the conclusion does not make use of "as," the latter merely "commented," as Bäck might say, on the relation between my belief and the "testimony of the senses."

However, there are different readings of "as." I propose that seeing-as can also be approached as seeing a perceptual qua-object. The perceptual qua-object is a composition of a certain perceived form or shape (or Gestalt) which stands for the "intellectual" or "testimonial" side, for this form is what we recognize, categorize, etc. The notion of form as applied to perception is alluded to by Wittgenstein himself when he makes use of the term "organization:"

The expression of a change of aspect is the expression of a new perception and at the same time of the perception's being unchanged.

I suddenly see the solution of a puzzle-picture. (...) My visual impression has changed and now I recognize that it has not only shape and colour but also a quite particular 'organization'.- (Ibid. 196)

The perceptual form is what fits our cognitive measures, so to speak, since it is such and such depending on the cognitive apparatus we have; most likely a bat faces different perceptual forms than I do, determined by the bat's specific cognitive apparatus. Yet, these differing perceptual forms may be attributed to one base to the effect that we-the bat and me-can see the same thing in two different ways. And the two constituents-the perceptual form and its base-are not two things which are mysteriously brought together; they are one and the same thing which presents itself in the guise of different base-gloss compounds. As I stressed before, the specificity of the qua-object is that you cannot disregard the base while focusing solely on the gloss, and neither can you disregard the gloss while paying attention to the base alone. So, it seems that targeting perception in terms of qua-objects is not at odds with what Wittgenstein had in mind when he spoke of the "amalgam" of the sensory and the intellectual insofar as the "intellectual" is understood, more broadly, as this component of perception that "speaks" to a particular perceiver, depending on the latter's specific cognitive equipment, thereby enabling this perceiver, but not necessarily a different one, to notice a specific aspect.

In my reading, the notion of perceptual qua-object helps to make it clear that we are offered by Wittgenstein a new way of thinking about perception and the mind-world relation more generally, enabling us not to take for granted the 
Cartesian dichotomy between the internal, intellectual and subjective realm on the one side, and the external, objective realm of receptors and sensations on the other side, which are supposed to come together in some mysterious way. The new framework takes a different conceptual distinctions to be fundamental, instead of the Cartesian external-internal or objective-subjective gulfs (I write more on this issue in Werner 2014, 2015, 2018).

\section{Some Additional Concerns}

There are several other problems that could be raised with respect to my account of "as." I address some of them briefly below. ${ }^{8}$

The first issue is the following: perhaps it is the case that the implication going from the additionally qualified proposition to the standard one is not an issue that deserves to be especially emphasized, but how about the implicature (in the sense of Grice 1969) from the additionally qualified proposition to the negation of a standard proposition. Namely, expressions such as "John is rational as a mathematician" seem to have a strong conversational implicature to the effect that John simpliciter is not rational. Say - that something must be wrong with his rationality if it needs an additional comment.

Addressing the problem of as-implicatures, if I can use such a term, in general would require a separate paper. So, at this point I flag two things. Firstly, I purposely omitted the issue of reduplicative propositions (of the form " $x$ qua (as) $x$ ") due to the lack of space, but once they are accounted for, I would argue that, actually, all propositions we use are additionally qualified, reduplicative or non-reduplicative, meaning that everything we say is additionally qualified, but it is pointless in most cases to bring it up. In most cases there is a shared tacit assumption made by the speakers as to which context or aspect of a discussed thing applies at a given moment. So the question is not whether or not "John is rational as a mathematician" conversationally implies "John is not rational," but whether or not the former conversationally implies "John as such (i.e. John qua John, to put it in the Aristotelian manner) is not rational." My provisional answer is "yes." If one wanted to share her belief in John's rationality without any additional comments, one would have to say "John as John (Jon as such) is rational," so if the latter has not been said, and one additionally qualifies her assessment of John's intellectual virtue, this means that the virtue at stake is restricted in some way; thus, that according to the speaker John as such does not have the virtue.

One could also ask whether or not negation can be built into the structure of asphrases, e.g. "John is irrational as not a mathematician" or "John is irrational as a non-mathematician." We can imagine a conversation of two mathematicians believing that only mathematicians are rational, therefore, if John does not belong to the said group, he should be deemed irrational. It is, arguably, a quite bizarre propositional structure, but at the end of the day, it may work well in some contexts when

\footnotetext{
${ }^{8}$ I thank the Reviewer for bringing these issues to my attention.
} 
articulated in terms of AP. But how about PQ, thus how about qua-objects with the built-in negation; are they plausible? Does it make a sense to attribute properties to, say, John as not a politician or John as a non-politician? My provisional answer is this: Formally, positing such negative qua-objects seems correct, but whether or not such a qua-object has, say, more substance to it, hinges on whether or not we can provide any positive characteristics of the attributed negative property which the qua-object is supposed to expose, e.g. the property of not being a politician (resp. the property of being a non-politician). As for the example given, it is doubtful. One who distrusts all politicians can say that all of them are liars, but one can hardly argue that all non-politicians are trustworthy since there are liars among the latter, too. So, it seems that there is no positive trait shared by all non-politicians, thus the negation produces a rather ad-hoc reference, and an ad-hoc negative qua-object.

Another interesting thing that deserves a separate debate is the issue of additional qualification applied to gradable properties, introducing contexts and restrictions in a different way, e.g. "John is tall for a jockey" or "John is short for a basketball player." They do not make an explicit use of "as," but the question is whether or not a suitable construction containing "as" could make justice to them. Moreover, note that this issue is related to the first one brought up above. Namely while "John as a basketball player is tall" seems to have a strong implicature that the additional qualification could be dropped and that John can be deemed tall disregarding his profession-which means here that he would be considered tall when compared to any average man-'John as a jockey is tall" seems to imply the opposite. Namely, he can be considered tall only when compared to his fellow jockeys, but he is not tall anymore when compared to an average man. My provisional answer brings the distinction between PQ and AP again. It seems at least provisionally plausible to try to account for the jockey case in terms of PQ. So, it can be unpacked as "(John as a jockey) is tall" meaning that if we take the relevant qua-object based on John, i.e. John wearing his jockey-aspect, the qua-object can count as tall, but John per se, thus the base of the qua-object at stake, does not inherit the property, just like the gold in the mentioned Tutankhamen case does not inherit the property of being a priceless work of art. On the other hand, we can approach "John is tall as a basketball player" in terms of AP. This means that the as-phrase merely "comments" on the property ascription: John is tall by any standards and the emphasize on his being a basketball player is supposed to bring this fact to our attention; and once the job is done, the as-phrase can be dropped, unlike in the jockey case where it is indispensable. These are, however, only provisional answers and the issue of gradable properties needs more work, too.

\section{Summary}

Additionally qualified propositions uncover and enable us to address what is usually tacit, namely how we recognize contexts and aspects of things when ascribing properties to them. They are useful and often used, however, scarcely addressed (Bäck's and Poli's studies are exceptional in this respect). The first thing that is usually addressed is whether or not the additionally qualified propositions can be 
approached as valid inferences. In this paper, I sought to take on the issue from a somewhat different angle and to ask first what contents-more often than not having some practical relevance — can be expressed by means of "as." It turned out that for many of these contents the question of whether they can serve as "condensed" inferences was irrelevant or misplaced. Hence, I decided to distinguish three groups or templates for "as." Afterward, I described several domains of enquiry in which the distinction may find potentially fruitful applications, including the puzzle of aspectual perception (Wittgenstein's "seeing-as").

Acknowledgements I would like to thank Colin Allen and Robert Goldstone for making it possible for me to present a part of this work at the Department of Psychological and Brain Sciences, Indiana University Bloomington in 2015. More recently I had a chance to come back to these issues thanks to Tadeusz Ciecierski and Tomasz Puczyłowski who invited me to their seminar "Znak-Język-Rzeczywistość" (Sign-Language-Reality) at the University of Warsaw - I am deeply grateful. Many thanks also to Józef Bremer and to all my colleagues from the Jagiellonian University in Kraków where I presented parts of this conception several times. Last but not least, many thanks to the reviewers of this paper. Finally, completing this work was supported by the grant UMO-2016/20/S/HS1/00046 provided by the National Science Centre, Poland.

Open Access This article is distributed under the terms of the Creative Commons Attribution 4.0 International License (http://creativecommons.org/licenses/by/4.0/), which permits unrestricted use, distribution, and reproduction in any medium, provided you give appropriate credit to the original author(s) and the source, provide a link to the Creative Commons license, and indicate if changes were made.

\section{References}

Angelelli I (1967a) Studies on Gottlob Frege and traditional philosophy. D. Reidel, Dordrecht

Angelelli I (1967b) On identity and interchangeability in Leibniz and Frege. Notre Dame J Form Log VIII 1\&2:94-100

Angelelli I (1978) Analytica Priora I 38 and reduplication. Notre Dame J of Form Log XIX 2:295-296

Annas JE (1976) Aristotle's metaphysics, books M and N, translated with introduction and notes. Oxford University Press, Oxford

Bäck A (1991) Qua. In: Burkhardt H, Smith B (eds) Handbook of metaphysics and ontology. Philosophia Verlag, Munich, pp 745-747

Bäck A (1996) On reduplication. Logical theories of qualification. E. J. Brill, New York

Bäck A (2002) The role of qualification. J Philos Res 27:159-171

Bäck A (2004) What is Being Qua Being? In: Coniglione F, Poli R, Rollinger R (eds) Idealization XI. Poznań studies in the philosophy of the sciences and the humanities, vol 82. Rodopi, New York, pp $37-58$

Bäck A (2014) Aristotle's theory of abstraction. Springer, Dordrecht

Barcan Marcus R (1995) Modalities: philosophical essays. Oxford University Press, Oxford

Barnes J (2000) Aristotle. A very short introduction. Oxford University Press, Oxford

Barth EM (1974) The logic of the articles in traditional philosophy. A contribution to the study of conceptual structures. D. Reidel, Dordrecht

Benardete JA (1989) Metaphysics: the logical approach. Oxford University Press, Oxford

Blum P (unpublished) Qua, qua, qua. Unpublished manuscript. http://philipp.philosophie.ch/hando uts/2013-8-1-qua.pdf. Accessed 17 April 2019

Bolzano B (1837) Wissenschaftslehre. Versuch einer ausführlichen und grösstentheils neuen Darstellung der Logik mit steter Rücksicht auf deren bisherige Bearbeiter, vol. 2. J. E. v. Seide, Sulzbach. [Quotation from the English translation: theory of science, vol 2. Oxford University Press, Oxford 2014]

Brewer B (2007) Perception and its objects. Philos Stud 132(1):87-97

Budd M (1987) Wittgenstein on seeing aspects. Mind XCVI(381):1-17 
Cohen J (2010) Color Relationalism and Color Phenomenology. In: Nanay B (ed) Perceiving the world. Oxford University Press, Oxford, pp 13-32

Crane T (2001) Elements of mind. Oxford University Press, Oxford

Crane T (2006) Is There a Perceptual Relation? In: Gendler T, Hawthorne J (eds) Perceptual experience. Oxford University Press, Oxford, pp 126-146

Day W, Krebs VJ (eds) (2010) Seeing Wittgenstein Anew. New essays on aspect-seeing. Cambridge University Press, Cambridge

Dretske F (1995) Naturalizing mind. MIT Press, Cambridge

Duarte S (2007) Aristotle's theology and its relation to the science of being qua being. Apeiron 40(3):267-318

Evnine SJ (2009) Constitution and qua objects in the ontology of music. Br J Aesthet 49(3):203-217

Fine K (1982) Acts, events, and things. In: Language and ontology. Proceedings of 6th international Wittgenstein symposium. Hölder-Pichler-Tempsky, Wien, pp 97-105

Fine K (1994) A puzzle concerning matter and form. In: Scaltsas T, Charles D, Gill ML (eds) Unity, identity, and explanation in Aristotle's metaphysics. Oxford University Press, Oxford, pp 13-40

Frege G (1893) Grundgesetze der arithmetic I. Verlag von Herman Pohle, Jena

Genone J (2014) Appearance and illusion. Mind 123(490):339-376

Gibson JJ (1979) The ecological approach to visual perception. Houghton Mifflin, Boston

Grice HP (1969) Utterer's meaning and intentions. Philos Rev 78:147-177

Johnson WE (1921) Logic. Part I. Cambridge University Press, Cambridge

Maritain J (1937) An introduction to logic. Sheed \& Ward, London

Marshall C (2013) Kant's appearances and things in themselves as qua-objects. Philos Q 63(252):520-545

Mates B (1986) Identity and predication in Plato. In: Knuuttila S, Hintikka J (eds) The logic of being. D. Reidel, Dordrecht, pp 29-47

McDowell J (2013) Perceptual experience: both relational and contentfull. Eur J Philos 21(1):144-157

Merriam-Webster. Retrieved June 16, 2016 from http://www.merriam-webster.com/dictionary/qua

Poli R (1994) Formal aspects of reduplication. Log Log Philos 2:87-102

Poli R (1999) Qua-theories. In: Albertazzi L (ed) Shapes of forms. Kluwer, Dordrecht, pp 245-256

Popper KR (1972) Objective knowledge: an evolutionary approach. Oxford University Press, Oxford

Quine WO $(1960,2013)$ Word and object. Quotations from Quine W v O, word and object. New edition. MIT Press, Cambrige

Oxford dictionaries. Retrieved June 16, 2016 from http://www.oxforddictionaries.com/definition/english/ qua

Schellenberg S (2008) The situation-dependency of perception. J Philos 105(2):55-84

Searle J (1992) The rediscovery of mind. MIT Press, Cambridge

Shani I (2010) Representation and aspectual shape. New Ideas Psychol 28(3):324-337

Siegel S (2016) The contents of perception. In: Zalta E (ed) The Stanford encyclopedia of philosophy. https://plato.stanford.edu/archives/win2016/entries/perception-contents/. Accessed 17 Apr 2019

Sokolowski R (1984) Intentional analysis and the Noema. Dialectica 38(1-2):113-129

Tapscott B (1976) Elementary applied symbolic logic. Prentice Hall, Englewood Cliffs

Varela F, Thompson E, Rosch E (1991) The embodied mind: cognitive science and human experience. MIT Press, Cambridge

Werner K (2014) Aspectual shape: presentational approach. Axiomathes 24(4):427-440

Werner K (2015) Towards a pl-metaphysics of perception: in search of the metaphysical roots of constructivism. Constr Found 11(1):148-157

Werner K (2018) Enactment and construction of the cognitive niche: toward an ontology of the mindworldconnection. Synthese. https://doi.org/10.1007/s11229-018-1756-1

Wiggins D (1980) Sameness and substance. Blackwell, Oxford

Wittgenstein L (1958) Philosophical investigations, 2nd edn. Basil Blackwell, Oxford

Publisher's Note Springer Nature remains neutral with regard to jurisdictional claims in published maps and institutional affiliations. 